Article

\title{
Understanding the Mechanism of Cypress Liquefaction in Hot-Compressed Water through Characterization of Solid Residues
}

\section{Hua-Min Liu ${ }^{1,2}$, Ming-Fei Li ${ }^{3}$, Sheng Yang ${ }^{3}$ and Run-Cang Sun ${ }^{2,3, *}$}

1 School of Grain and Food, Henan University of Technology, Zhengzhou 450001, China; E-Mail: liuhuamin5108@163.com

2 State Key Laboratory of Pulp and Paper Engineering, South China University of Technology, Guangzhou 510640, China

3 Institute of Biomass Chemistry and Technology, Beijing Forestry University, Beijing 100083, China; E-Mails: lmfeifei@sina.com (M.-F.L.); E-Mail: yangsheng113112@126.com (S.Y.)

* Author to whom correspondence should be addressed; E-Mail: rcsun@scut.edu.cn; Tel./Fax: +86-10-6233-6903.

Received: 26 November 2012; in revised form: 4 February 2013 / Accepted: 28 February 2013 / Published: 11 March 2013

\begin{abstract}
The mechanism of hydrothermal liquefaction of cypress was investigated by examining the effects of temperature and retention time on the characteristics of the solid residues remaining after liquefaction. The solid residues were divided into acid-soluble and acid-insoluble residues. Results showed the polymerization reactions also mainly occurred at low temperatures. The reactive fragments transformed into acid-insoluble solid residue in the form of carbon and oxygen through polymerization reactions. The process of cellulose degradation consists of two steps: an initial hydrolysis of the more solvent- accessible amorphous region and a later hydrolytic attack on the crystalline portion. Hemicelluloses were decomposed into small compounds during the initial stage of the cypress liquefaction process, and then these compounds may rearrange through polymerization to form acid-insoluble solid residues above $240{ }^{\circ} \mathrm{C}$. The higher heating value of the solid residues obtained from liquefaction at $260-300{ }^{\circ} \mathrm{C}$ was $23.4-26.3 \mathrm{MJ} / \mathrm{kg}$, indicating that they were suitable for combustion as a solid fuel.
\end{abstract}

Keywords: liquefaction; acid-insoluble solid residue; reaction mechanisms; sugar analysis 


\section{Introduction}

Thermo-chemical conversion technologies can efficiently convert biomass to gaseous, liquid, and solid products under thermal conditions [1]. Pyrolysis and liquefaction are the typical thermo-chemical processes for the conversion of biomass to produce liquid products in high yields. During the pyrolysis process, biomass is heated in the absence of air, forming bio-oils and gaseous products [2]. Liquefaction technology as a widely used method has a lower process temperatures as compared to pyrolytic conversion. In liquefaction processes, biomass depolymerizes in the presence of organic reagents to form useful chemicals [3,4]. The bio-oils cannot be used as transportation fuels directly without further treatment due to their high oxygen and water contents. Catalytic pyrolysis liquefaction is a promising way to improve bio-oil quality by removing oxygen, while also increasing the calorific value and stability [5]. However, the use of environmentally friendly and low energy-intensive approaches is highly desired. Hot-compressed and super/subcritical water have been widely studied and developed as technologies for the conversion of biomass to clean fuel and valuable chemicals [6,7]. The main advantage of these technologies is that drying process is not required for the conversion of wet biomass, because the water contained in biomass served as solvent as well as reactant [7].

Detailed data for bio-oils are good for understanding the mechanism of biomass. In recent years, although bio-oils have been analyzed by GC-MS, FT-IR, and NMR in many reports $[5,6,8]$, the degradation of biomass cannot be easily described by detailed chemical reaction pathways with well-defined single reaction steps. This is mainly due to the complexity of the bio-oil components, which include acids, alcohols, aldehydes, ketones, esters, heterocyclic derivatives, and phenolic compounds as products of the degradation of biomass [9]. Another reason for the difficulty in describing the chemical reaction pathways is that the liquefaction is mainly a heterogeneous process, which proceeds inside and on the surface of biomass particles [10]. Numerous works use thermo-gravimetric analysis to determine thermal decomposition of biomass mechanisms and estimate the amounts of biogas (such as methane and hydrogen) produced during the pyrolsis process [11,12]. However, the analytical technology cannot investigate the effect of solvent on the thermal characteristics and mechanism of biomass liquefaction. Although the liquefaction of biomass using different solvents has been investigated, there is little information on the thermal behavior of solvents in these liquefaction processes.

Many researchers have also evaluated the characteristics of the solid residue from hydrothermal liquefaction of biomasses by using FT-IR [13-15]. However, the biomass is a polymer with a particularly complex structure, and therefore, FT-IR alone is not enough to study the hydrothermal liquefaction of biomass. However, more information from the infrared analysis of solid residues may help to better understand the liquefaction processes. To the best of our knowledge, in the previous investigations focused on the evaluation of the characteristics of whole solid residues by using techniques such as FT-IR, X-ray diffraction, and NMR few attempts have been made to first divide the solid residues into different fractions, and then further investigate the characteristics of these various fractions.

In the present study, the solid residues obtained from hydrothermal liquefaction of cypress under different conditions (temperature and retention time) were divided into acid-soluble and acid-insoluble solid residues by hydrolysis with dilute sulfuric acid, and then the acid-insoluble solid residues further 
divided into carbon, hydrogen, and oxygen by the elemental analyzer. The effects of temperature and retention time on the yields of different fractions were studied. Additionally, the solid residues (included acid-soluble and acid-insoluble solid residues) were characterized by FT-IR, X-ray diffraction, sugar analysis, and elemental analysis to help understand the mechanisms of the hydrothermal liquefaction process.

\section{Experimental Section}

\subsection{Materials}

Cypress was collected from Henan Province in China. The feedstock was milled to obtain fine powder by passing through 40 -mesh. The powder was dried at $105^{\circ} \mathrm{C}$ for $24 \mathrm{~h}$ before used. The dried cypress contained $43.2 \%$ cellulose, $26.3 \%$ hemicelluloses, $28.2 \%$ lignin, $48.9 \%$ carbon, $44.8 \%$ oxygen, $6.0 \%$ hydrogen, $0.3 \%$ nitrogen, and $2.5 \%$ ash (on a dry weight basis). The chemicals used were analytical reagent grade.

\subsection{Apparatus and Experimental Procedure}

Cypress sample $(10 \mathrm{~g})$ and de-ionized water $(100 \mathrm{~mL})$ were placed in a $1 \mathrm{~L}$ stainless steel autoclave equipped with a magnetic stirrer (Parr Instrument Company, Moline, IL, USA). The details of the liquefaction experiments were described previously [16]. The scheme of the product separation and analysis approach is shown in Figure 1. The reaction mixture was filtered to separate the water-soluble fraction and then the water-insoluble fraction was extracted with acetone in an extraction apparatus until the solvent in the thimble became colorless. The acetone-insoluble fraction was dried at $105{ }^{\circ} \mathrm{C}$ and then weighed, and this was defined as solid residue (SR). The carbohydrates present in the SRs obtained at different conditions were removed by hydrolysis with $3 \% \mathrm{H}_{2} \mathrm{SO}_{4}$ for $4 \mathrm{~h}$ at $100{ }^{\circ} \mathrm{C}$. Therefore, the solid residues were further divided into acid-soluble solid residue (ASSR) and acid-insoluble solid residue (AISR). The acid-insoluble solid residues were further divided into carbon, oxygen, and hydrogen by the elemental analyzer. The yield of solid residue was calculated on a dry-ash-free basis and each experiment was repeated twice.

\subsection{Analysis}

The carbon, hydrogen, and nitrogen contents of cypress and solid residues were analyzed using an Elemental Analyzer (Elementar Analysen Syetem GmbH, Hanau, Germany). The oxygen content was estimated based on the assumption that the samples only contained the elements carbon, hydrogen, nitrogen, and oxygen. The higher heating values (HHV) of the samples were calculated based on Dulong formula, as described previously [16].

The SRs were evaluated using an X-ray diffractometer to determine the degree of crystallinity. X-ray diffractometry in reflection mode was conducted using a X-ray diffractometer (Shimadzu XRD-6000, Tokyo, Japan) with Cu Ká radiation source $(\ddot{e}=0.154 \mathrm{~nm})$ at $40 \mathrm{kV}$ and $30 \mathrm{~mA}$. The crystallinity index $(\mathrm{Cr} I)$ was calculated based on the formula as reported in a previous paper [17].

The neutral sugar composition of the cypress and SRs obtained from hydrothermal liquefaction was determined by hydrolysis with $3 \% \mathrm{H}_{2} \mathrm{SO}_{4}$ for $2.5 \mathrm{~h}$ at $105{ }^{\circ} \mathrm{C}$. The liberated neutral sugars were 
analyzed by high performance anion exchange chromatography (Dionex ICS-3000, Sunnyvale, CA, USA) and a Carbopac PA-1 ion exchange column $(4 \times 250 \mathrm{~mm})$.

Fourier transform infrared spectrometer (FT-IR) analysis of raw cypress, acid-insoluble lignin, SRs, and AISRs were carried out on a Nicolet iN10 FT-IR spectrophotometer (Madison, WI, USA) equipped with a liquid nitrogen-cooled MCT detector. The raw cypress material was heated at $650{ }^{\circ} \mathrm{C}$ for $6 \mathrm{~h}$ to determine the ash content.

Figure 1. A brief scheme of the product separation and analysis approach.

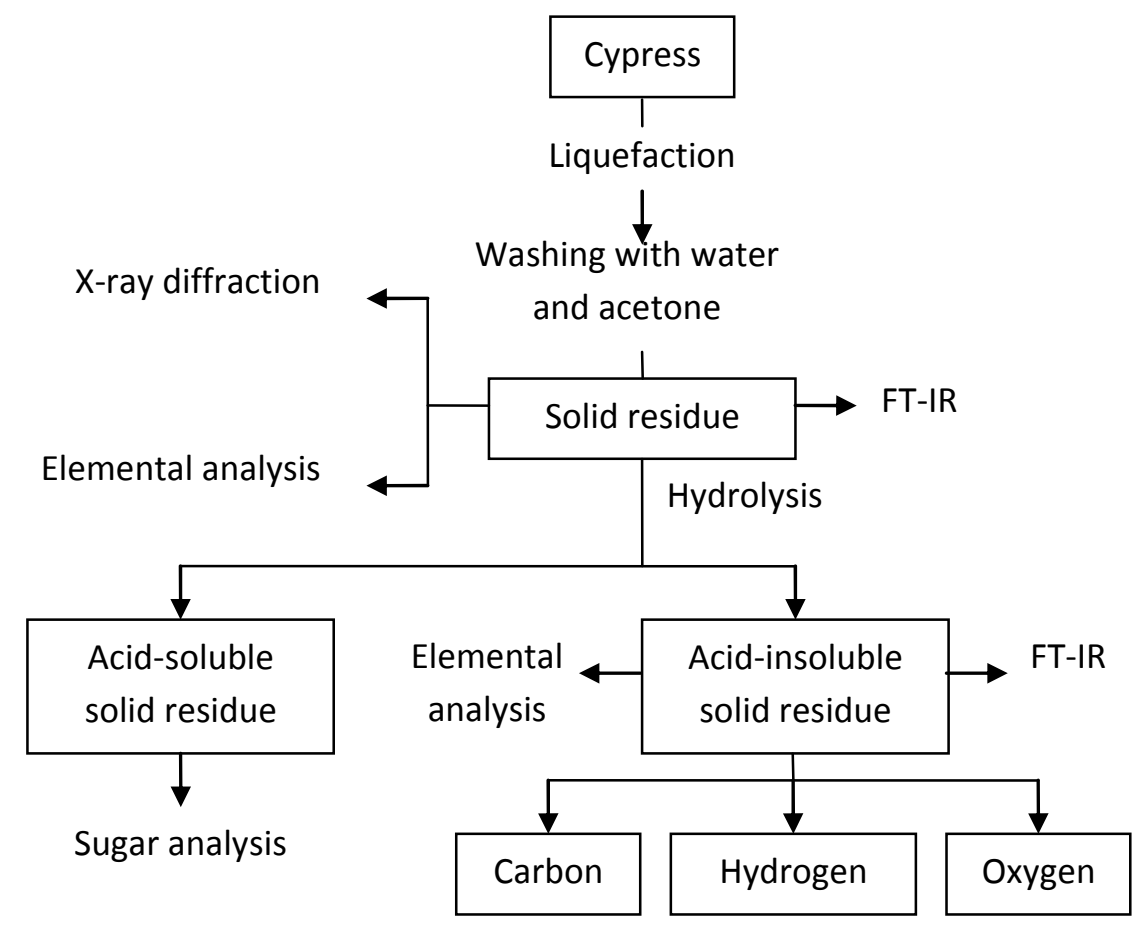

\section{Results and Discussion}

\subsection{The Yield of Solid Residue}

\subsubsection{Effect of Temperature on Yield of Solid Residue}

The yields of the SR obtained from hydrothermal liquefaction of cypress at various temperatures are shown in Figure 2a. The lower the temperature and pressure, the higher the SR yields. The SR yield firstly decreased from 85.9 to $36.2 \%$ as the final temperature increased from 180 to $260{ }^{\circ} \mathrm{C}$. Then, the yield of SR increased to $39.5 \%$ with a temperature increase to $300{ }^{\circ} \mathrm{C}$. The decrease in the yield of SR with an increase temperature could be due to the decomposition of cypress. This trend of SR yield against temperature was consistent with the results in literature for other biomass types. Xiu et al. [18] have investigated hydrothermal liquefaction of swine manure and found that the yield of SR first decreased and then increased with the increase in temperature. Similarly, hydrothermal liquefaction of paulownia also showed that high temperatures $\left(>320{ }^{\circ} \mathrm{C}\right)$ enhanced the yield of SR [19]. They concluded that it was due to the competition of two reactions (hydrolysis and polymerization) involved in the hydrothermal liquefaction process and it is widely accepted that the polymerization reactions are 
the main reaction at high temperatures [18,19]. Figure 2(a-1) shows that the yield of ASSR (carbohydrates) decreased over the whole temperature range, and the yield of AISR increased after $220^{\circ} \mathrm{C}$. Hence in the present study, the results indicated that the polymerization reactions were also mainly present at lower temperatures (above $220{ }^{\circ} \mathrm{C}$ ). The polymerization reactions involve free radicals which are produced from further decomposition of fragments from the initial decomposition of cypress. The free radicals then undergo polymerization reactions, producing higher molecular weight, insoluble polymers, which contributed to the increase of the AISR yield [20]. The carbon and oxygen contents in the solid residue decreased with the increase of temperature from 180 to $220{ }^{\circ} \mathrm{C}$, and then increased with the final temperature increase from 240 to $300^{\circ} \mathrm{C}$. The final increase in yield is likely to be due to the transformation of reactive fragments into AISR as the polymerization reactions increased the amount of carbon and oxygen in the AISR in the temperature range of $240-300{ }^{\circ} \mathrm{C}$.

Figure 2. Effect of (a) temperature and (b) retention time on the yield of solid residue.
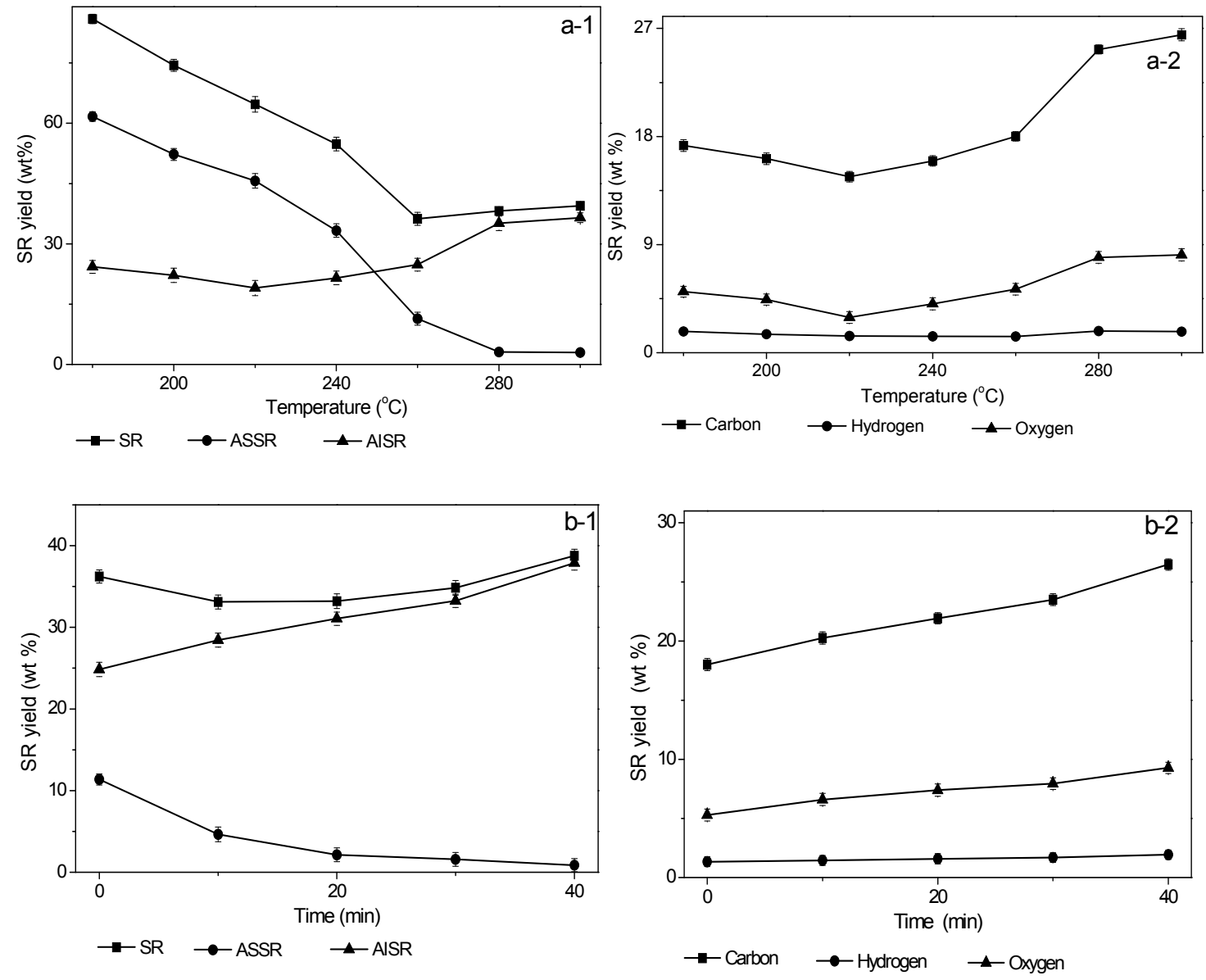

\subsubsection{Effect of Retention Time on Yield of Solid Residue}

Figure 2(b-1) shows the effect of retention time on the SR yield from hydrothermal liquefaction of cypress. Retention time had a lower influence on the yield of SR as compared to reaction temperature. Ten minutes of retention time at $260{ }^{\circ} \mathrm{C}$ were sufficient for cypress liquefaction which gave the highest conversion yield (100\%-SR yield). The yield of ASSR decreased as the retention time was prolonged due to the formation of small compounds from the hydrolysis of the carbohydrates. The yield of AISR increased as the yield of ASSR decreased with retention time, which suggested the occurrence of the 
hydrolysis and polymerization reactions. The dependence of the carbon and oxygen contents in solid residues on the retention time is shown in Figure 2(b-2), where it can be seen that the carbon and oxygen contents increased continuously with the increase in retention time over the whole time range. The increase of the carbon and oxygen yields, indicated polymerization of the novel compounds had occurred which resulted in higher carbon and oxygen content in AISR. Since the longer retention time resulted in a lower conversion yield, a shorter retention time of approximately $0-10 \mathrm{~min}$ was preferred.

\subsection{Crystallinity of Solid Residue}

To examine the crystalline forms in the cypress before and after hydrothermal liquefaction, X-ray diffraction (XRD) measurements were carried out. Figure 3 illustrates the XRD spectra of the cypress powder before and after hydrothermal liquefaction at various temperatures (180, 200, 220, 240, 260, 280 , and $300{ }^{\circ} \mathrm{C}$ ) and at $260{ }^{\circ} \mathrm{C}$ for various retention times (10, 20, 30, and $\left.40 \mathrm{~min}\right)$. The XRD pattern of the raw cypress showed two peaks at $2 \grave{e}=16.8^{\circ}$ and $22.0^{\circ}$, typical of cellulose $\mathrm{I}$. These peaks have been well documented and correspond to the (110) and (200) planes of cellulose, respectively. As shown in Figure 3a, in the case of the hot-compressed water treatment, the peak at $22.0^{\circ}$ present in the raw cypress diffraction pattern shifted to $22.6^{\circ}$, indicating that there was a structural order change in the cellulose after liquefaction.

Figure 3. X-ray diffraction patterns of the raw cypress before and after hydrothermal liquefaction: (a) the raw cypress before and after hydrothermal liquefaction at different temperatures; and (b) the raw cypress after hydrothermal liquefaction at different retention times.
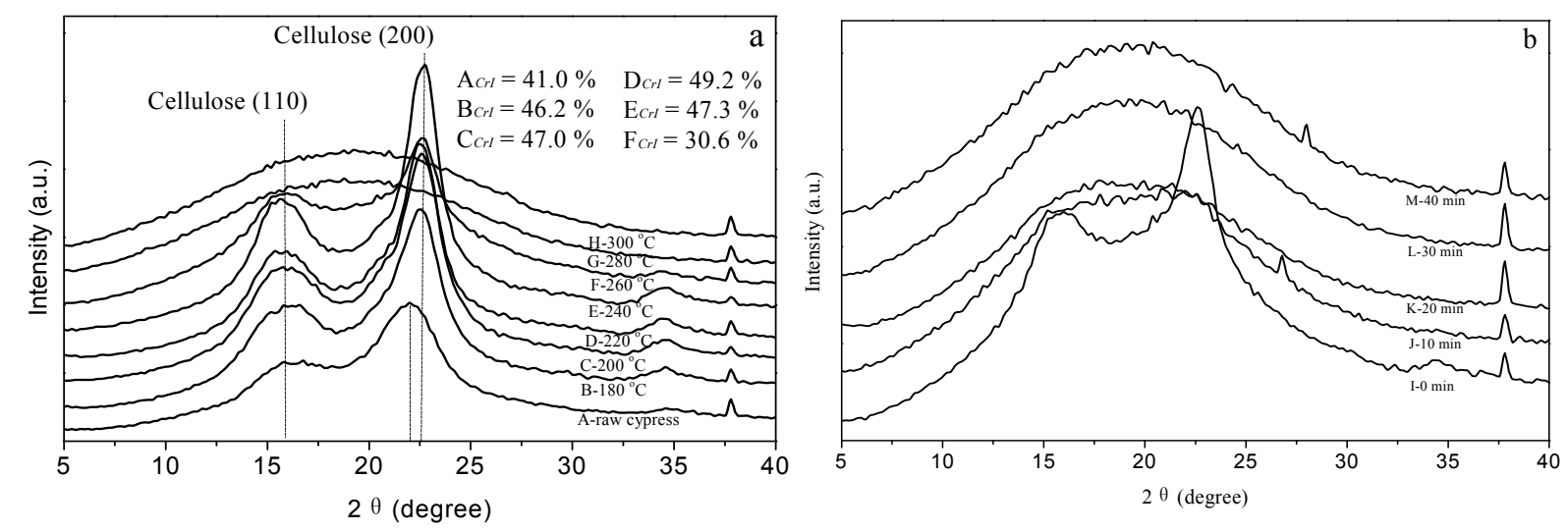

For the SRs obtained at the higher temperatures $\left(280\right.$ and $\left.300{ }^{\circ} \mathrm{C}\right)$ and at $260{ }^{\circ} \mathrm{C}$ for 10 to $40 \mathrm{~min}$, the two peaks derived from cellulose I weakened. The crystallinity index $(\mathrm{Cr} I)$ for raw cypress and the SRs obtained from liquefaction at the temperatures from 180 to $260{ }^{\circ} \mathrm{C}$ was calculated from the XRD data and the results are summarized in Figure $3 \mathrm{a}$. The $\mathrm{CrI}$ of the raw cypress was about $41.0 \%$ due to the existence of a large amount of amorphous substances including lignin and hemicelluloses. After the hydrothermal liquefaction, the $C r I$ increased to $49.2 \%$ at $220{ }^{\circ} \mathrm{C}$, which suggested that there was a remarkable increase in the relative amount of crystalline matter with the decomposition of the amorphous components. The $C r I$ showed a tendency to decline with increasing temperature, which 
could be attributed to the crystal structure change, cellulose amorphization or the changes in the microscopic structures of the lignocellulose particles after the treatment at the higher temperatures.

\subsection{Sugar Analysis of Solid Residue}

The main sugars of the cypress were glucose (mainly from cellulose) which accounted for about $21.3 \%$ of the sample followed by mannose (from hemicelluloses), which accounted for $11.8 \%$. Small amounts of xylose, galactose, and arabinose were also detected. The monosaccharide sugar compositions of SRs from hydrothermal liquefaction of cypress at various temperatures and retention times are shown in Figure 4.

Figure 4. Sugar analysis of solid residues: (a) Effect of temperature on the yields of cellulose and hemicelluloses; (b) Effect of temperature on the yields of sugar; and (c) Effect of retention time on the yields of sugar.
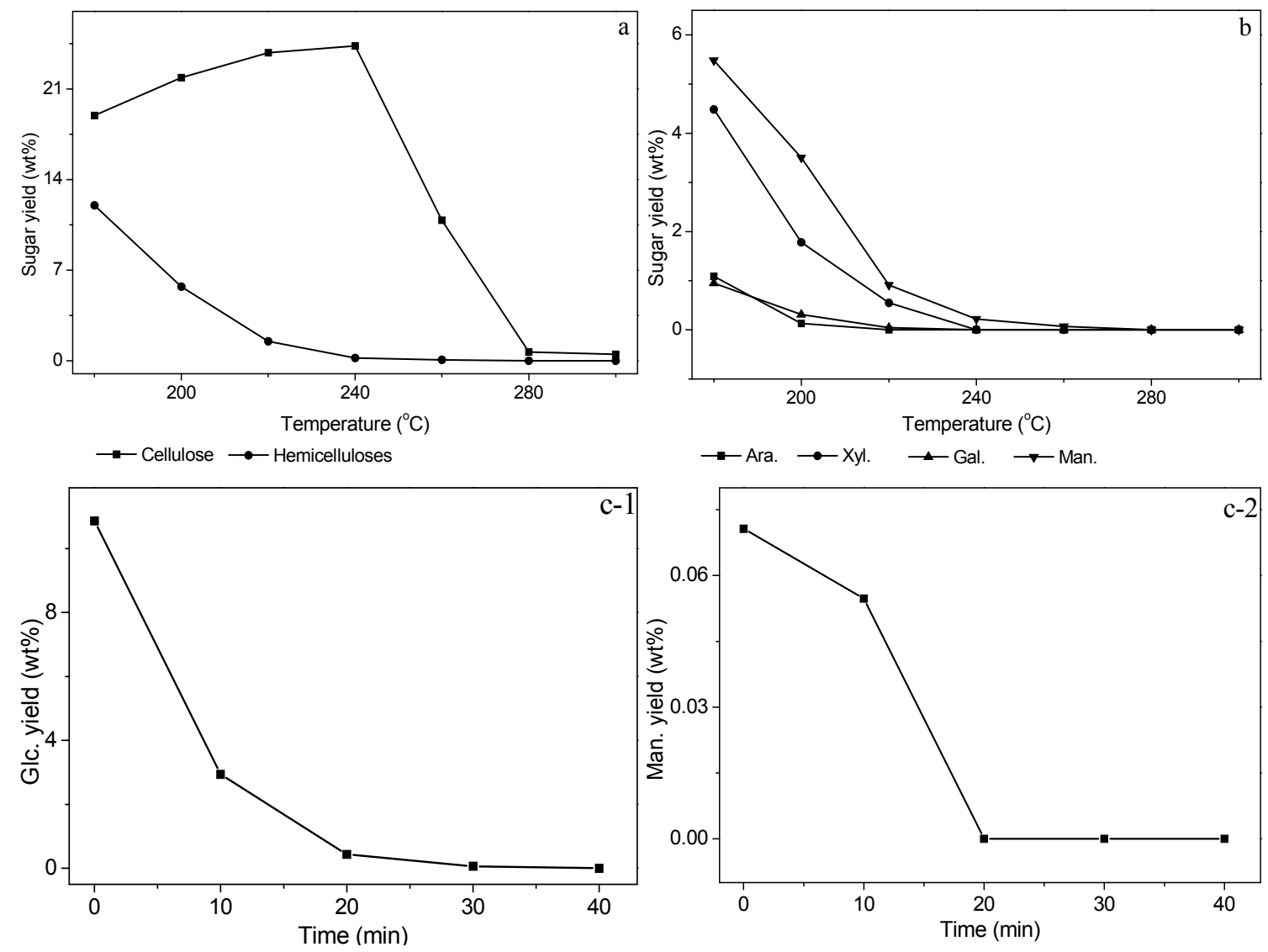

The content of cellulose initially increased with the increase in retention temperature, and then decreased with a further increase in temperature and almost no cellulose was detected at 280 and $300{ }^{\circ} \mathrm{C}$. The increase of the cellulose yield at lower temperatures was caused by the decomposition of hemicelluloses. Coupling these results with the results from the XRD analysis, indicated that the majority of the cellulose in cypress was decomposed at the high temperatures $\left(>280{ }^{\circ} \mathrm{C}\right)$. In a simple cypress decomposition mechanism, hemicelluloses would be the first to decompose at low temperatures $\left(180{ }^{\circ} \mathrm{C}\right)$ followed by intermediate temperature lignin decomposition, while cellulose decomposes at relatively higher temperatures $\left(>240{ }^{\circ} \mathrm{C}\right)[21,22]$. Other important results are also 
summarized in Figure 4b, where xylose and galactose were not detected after $220{ }^{\circ} \mathrm{C}$, while the arabinose and mannose were disappeared after 200 and $260{ }^{\circ} \mathrm{C}$, respectively. This supported the simple model of biomass decomposition and indicated that the hemicelluloses decomposed at temperatures of 180 to $260{ }^{\circ} \mathrm{C}$, while cellulose followed at temperatures of 240 to $280{ }^{\circ} \mathrm{C}$.

Figure $4 \mathrm{c}$ shows the effect of retention time on the yields of sugar from 0 to $40 \mathrm{~min}$ at $260{ }^{\circ} \mathrm{C}$. The yields of glucose and mannose dropped remarkably to 0 with the prolongation of retention time from 20 to $40 \mathrm{~min}$. The reactions in the biomass decomposition process were much complex. Determine exactly what types of reactions occur during hydrothermal liquefaction process is difficult. Liquefaction of carbonaceous materials took place through a sequence of structural and chemical changes, which involved at least the following steps: (1) solvolysis of biomass resulting in micellar-like structures; (2) degradation of cellulose, hemicelluloses, and lignin; and (3) chemical and thermal decomposition of monomers to form smaller components such as phenols, acids, ketones, liquid hydrocarbons, gaseous products, and SRs by fragmentation, condensation, dehydration, and isomerization pathways [22, 23].

\subsection{FT-IR Analysis}

\subsubsection{FT-IR Analysis of Solid Residue}

The FT-IR spectra of the cypress before and after hydrothermal liquefaction were investigated. Cypress is mainly composed of cellulose, hemicelluloses, and lignin and the bands in the spectra of the raw cypress and SRs have been previously assigned [22,24]. The absorption at $1722 \mathrm{~cm}^{-1}(\mathrm{C}=\mathrm{O}$ stretching vibration, carbonyl, and ester groups) represents the xylans of hemicelluloses. Cellulose has its characteristic absorption peaks at $3362 \mathrm{~cm}^{-1}$ (-OH stretching vibration), $2900 \mathrm{~cm}^{-1}\left(-\mathrm{CH}_{3},-\mathrm{CH}_{2}\right.$ stretching), $1365 \mathrm{~cm}^{-1}$ (- $\mathrm{CH}_{3}$ bending vibration), $1022 \mathrm{~cm}^{-1}$ (C-O bending vibration), and $888 \mathrm{~cm}^{-1}$ (anomeric carbon vibration). Lignin showed distinct bands mainly at 1600-1590, 1520-1500, and $1416 \mathrm{~cm}^{-1}$ due to benzene ring stretching vibrations.

A comparison of combination infrared spectra is drawn between the raw cypress and the SRs obtained at various temperatures. As seen from Figure 5a, the band at $1722 \mathrm{~cm}^{-1}$ almost disappeared after the $200{ }^{\circ} \mathrm{C}$ liquefaction, indicating that hemicelluloses decomposition preceded lignin and cellulose. The sharp absorption at $1365 \mathrm{~cm}^{-1}$ of the SR disappeared at 280 and $300{ }^{\circ} \mathrm{C}$, which indicated that the cellulose crystals were degraded [19]. At the same time, the disappearance of the characteristic absorption peak at $1520 \mathrm{~cm}^{-1}$ indicated that lignin had been decomposed. These results were consistent with many previous studies on hydrothermal liquefaction of biomass: hemicelluloses is the first to decompose at low temperature $\left(180{ }^{\circ} \mathrm{C}\right)$, lignin began to degrade at $190{ }^{\circ} \mathrm{C}$, and all of the hemicelluloses and much of the lignin dissolved in the water at $220^{\circ} \mathrm{C}$ to form intermediates $[18,19]$. A new band at $1702 \mathrm{~cm}^{-1}$ was found after $240{ }^{\circ} \mathrm{C}$. The $1702 \mathrm{~cm}^{-1}$ is most likely derived from the unconjugated ketone and carboxyl group stretching. This result could be explained by the FT-IR analysis of AISR below. 


\subsubsection{FT-IR Analysis of Acid-insoluble Solid Residue}

To further investigate the structural changes of the cypress after hydrothermal liquefaction at various temperatures, the SR was further divided into ASSR and AISR. The FT-IR spectra of the acid-insoluble lignin and AISR after liquefaction at various temperatures were comparatively investigated. The typical FT-IR spectra of the acid-insoluble lignin and the AISRs obtained at various temperatures are shown in Figure 5b. According to the literatures [24-26], the bands at 1599, 1504, and $1415 \mathrm{~cm}^{-1}$ are attributed to aromatic skeleton vibrations in the acid-insoluble lignin. The band at about $1711 \mathrm{~cm}^{-1}$ is assigned to the unconjugated ketone and carboxyl group stretching. Absorption at $1456 \mathrm{~cm}^{-1}$ is due to methoxyl C-H deformations and bending of lignin. In the wavenumber region from 1200 to $1300 \mathrm{~cm}^{-1}$, the bands at 1262 and $1205 \mathrm{~cm}^{-1}$ are attributed to aromatic carbon-oxygen (in methoxyl and phenol groups) stretching vibrations from guaiacyl units. $\mathrm{C}-\mathrm{H}$ in-plane bending in guaiacyl lignin is assigned at 1142 and $1026 \mathrm{~cm}^{-1}$. Aromatic $\mathrm{C}-\mathrm{H}$ out-of-plane bending appears at $864 \mathrm{~cm}^{-1}$. The band at $1142 \mathrm{~cm}^{-1}$ almost disappeared after $280{ }^{\circ} \mathrm{C}$. This indicated that the structure of $\mathrm{C}-\mathrm{H}$ in-plane bending in guaiacyl lignin had disappeared after $280{ }^{\circ} \mathrm{C}$. As seen from the spectra, the band at $1415 \mathrm{~cm}^{-1}$ had disappeared in the sample from the $300{ }^{\circ} \mathrm{C}$, which confirmed that the "core" of the lignin structure was slightly changed at the highest temperature treatment. Interestingly, remarkable increases of unconjugated ketone and carboxyl group stretching in the AISR obtained after $240{ }^{\circ} \mathrm{C}$ were observed. Based on the FT-IR analysis of SRs, all of the hemicelluloses decomposed in water after $220^{\circ} \mathrm{C}$ and the new band of $1702 \mathrm{~cm}^{-1}$ was found after $240{ }^{\circ} \mathrm{C}$. A possible explanation for the observed spectral changes is that hemicelluloses were decomposed to small compounds at the initial lower temperatures stage, and then these compounds may have rearranged through polymerization to form AISR after $240{ }^{\circ} \mathrm{C}$.

Figure 5. FT-IR analysis of the (a) solid residue and (b) acid-insoluble solid residue.
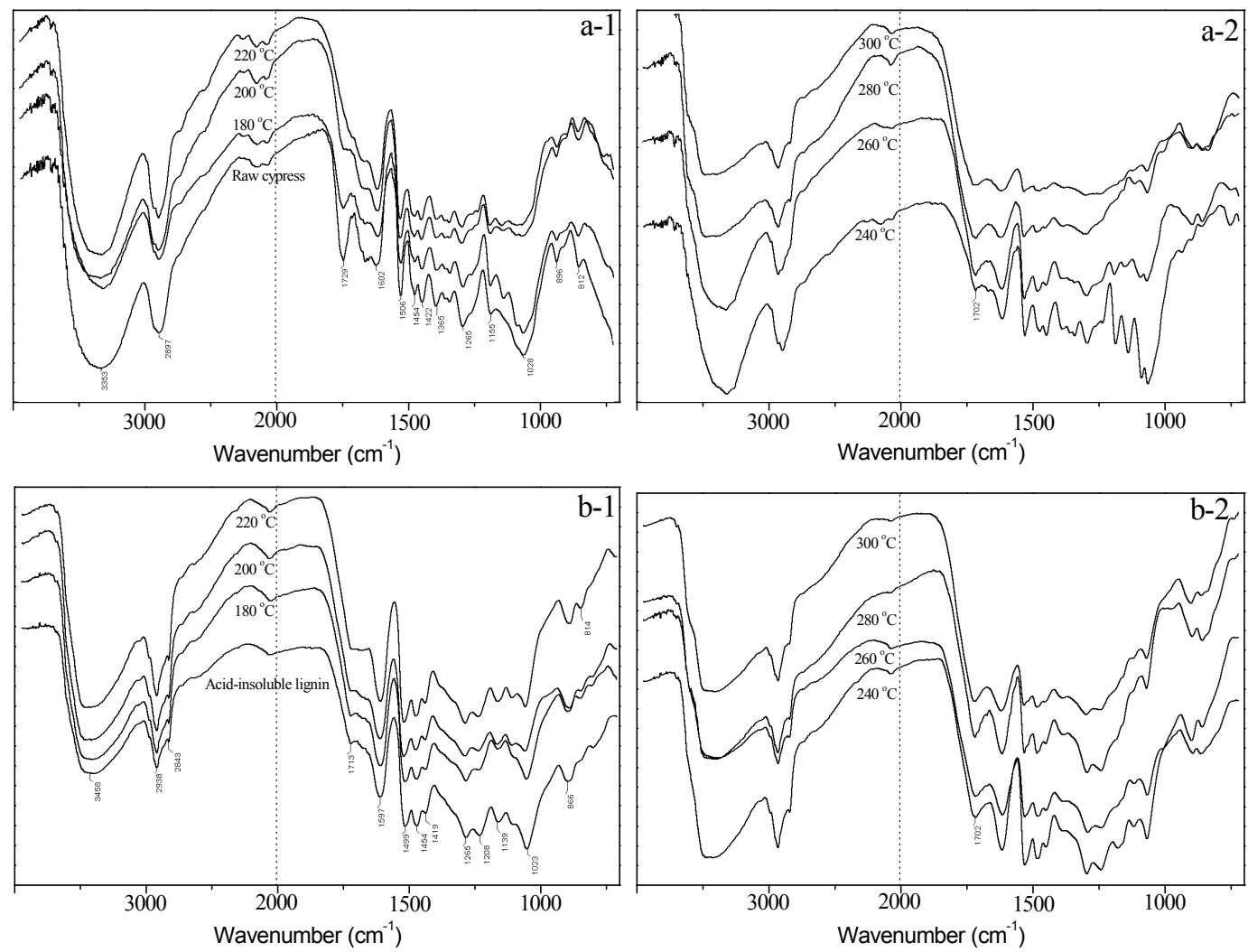


\subsection{Elemental Analysis and Higher Heating Value of Solid Residues}

Biomass contains much more oxygen and less carbon with a lower heating value in comparison with petroleum, therefore the key point to convert biomass into useful fuels is to remove oxygen from the original biomass [27]. Higher heating value (HHV) is an important fuel property which defines the energy content of the fuel. Estimation of HHV from the elemental composition of fuel is one of the basic steps in performance modeling and calculations on thermal systems. The elemental compositions of the SRs produced from hydrothermal liquefaction under different experimental conditions were investigated and the results are given in Table 1 . The experimental conditions were found to have a large effect on the char composition. The carbon content in the SR increased from $49.1 \%$ to $70.1 \%$ and the oxygen content decreased from $44.6 \%$ to $24.7 \%$ with a temperature increase from 180 to $300{ }^{\circ} \mathrm{C}$. Consequently, a large variation was observed in the HHV ranging from 17.4 to $26.3 \mathrm{MJ} / \mathrm{kg}$. Retention time appears to have less influence on the SR as compared to temperature. The carbon content increased and the oxygen content decreased with the increase in retention time which resulted in SR with a high HHV. The HHV of SRs from hydrothermal liquefaction of cypress at the high temperatures $\left(260,280\right.$, and $300{ }^{\circ} \mathrm{C}$ ) were 23.4 to $26.3 \mathrm{MJ} / \mathrm{kg}$, much close to that of the Xuzhou coal (23.22 MJ/kg) [28] and the Loy yang coal (26.4 MJ/kg) [29]. These values demonstrate that the SRs have potential as the solid fuels to replace coal. Additionally, the heat loss per unit mass of energy produced was significantly low, making the liquefaction process produce more energy overall.

Table 1. Elemental analysis of the solid residues and HHV.

\begin{tabular}{|c|c|c|c|c|c|c|c|}
\hline \multirow{2}{*}{ Samples } & \multicolumn{4}{|c|}{ Elemental components (wt \%) } & \multirow{2}{*}{$\mathbf{O} / \mathbf{C}$} & \multirow{2}{*}{$\mathbf{H} / \mathbf{C}$} & \multirow{2}{*}{ HHV (MJ/kg) } \\
\hline & $\mathrm{C}$ & $\mathbf{H}$ & $\mathbf{O}$ & $\mathbf{N}$ & & & \\
\hline $180^{\circ} \mathrm{C}$ & 49.1 & 6.1 & 44.6 & $<0.3$ & 0.90 & 0.12 & 17.4 \\
\hline $200^{\circ} \mathrm{C}$ & 50.1 & 6.0 & 43.8 & $<0.3$ & 0.87 & 0.12 & 17.6 \\
\hline $220^{\circ} \mathrm{C}$ & 51.2 & 6.1 & 42.6 & $<0.3$ & 0.83 & 0.12 & 18.4 \\
\hline $240{ }^{\circ} \mathrm{C}$ & 53.7 & 5.9 & 40.2 & $<0.3$ & 0.75 & 0.11 & 19.4 \\
\hline $260^{\circ} \mathrm{C}$ & 62.5 & 5.5 & 31.6 & 0.42 & 0.51 & 0.088 & 23.4 \\
\hline $280^{\circ} \mathrm{C}$ & 69.4 & 5.1 & 25.2 & 0.43 & 0.36 & 0.073 & 26.2 \\
\hline $300{ }^{\circ} \mathrm{C}$ & 70.1 & 4.9 & 24.7 & 0.41 & 0.35 & 0.070 & 26.3 \\
\hline $10 \min$ & 66.9 & 5.2 & 27.5 & 0.45 & 0.41 & 0.078 & 25.1 \\
\hline $20 \mathrm{~min}$ & 68.7 & 5.1 & 25.8 & 0.42 & 0.38 & 0.074 & 25.9 \\
\hline $30 \mathrm{~min}$ & 69.3 & 5.1 & 25.3 & 0.44 & 0.37 & 0.073 & 26.2 \\
\hline $40 \mathrm{~min}$ & 69.2 & 5.1 & 25.2 & 0.46 & 0.36 & 0.073 & 26.2 \\
\hline
\end{tabular}

\subsection{Investigation of Presumed Hydrothermal Liquefaction Mechanism}

To clarify the mechanism for hydrothermal liquefaction, a simple reaction model of hydrothermal liquefaction of cypress is postulated in Figure 6 and Schemes 1 and 2. On the basis of the above results, the basic reaction mechanisms can be described as three steps (Figure 6). Firstly, the amorphic structure of the hemicelluloses and cellulose was decomposed. Secondly, the crystalline cellulose was decomposed by hydrolysis and the AISR was formed by polymerization reactions. Finally, reactive fragments recombined to form more AISR. The degradation of cellulose is an acid-catalyzed and thermally accelerated chain scission mechanism [30]. The degradation process consists of two steps: 
an initial hydrolysis of the amorphous region which is more easily accessed by the solvent and a latter hydrolytic attack of the crystalline portion [31,32]. Previous researchers reported that one of the most important types of compounds present in bio-oil obtained from hydrothermal liquefaction of biomass were weak acids such as acetic acid, formic acid, and levulinic acid [5,6,9]. The acids were mainly produced from the decomposition of hemicelluloses and cellulose.

Figure 6. Mechanism for hydrothermal liquefaction of cypress.

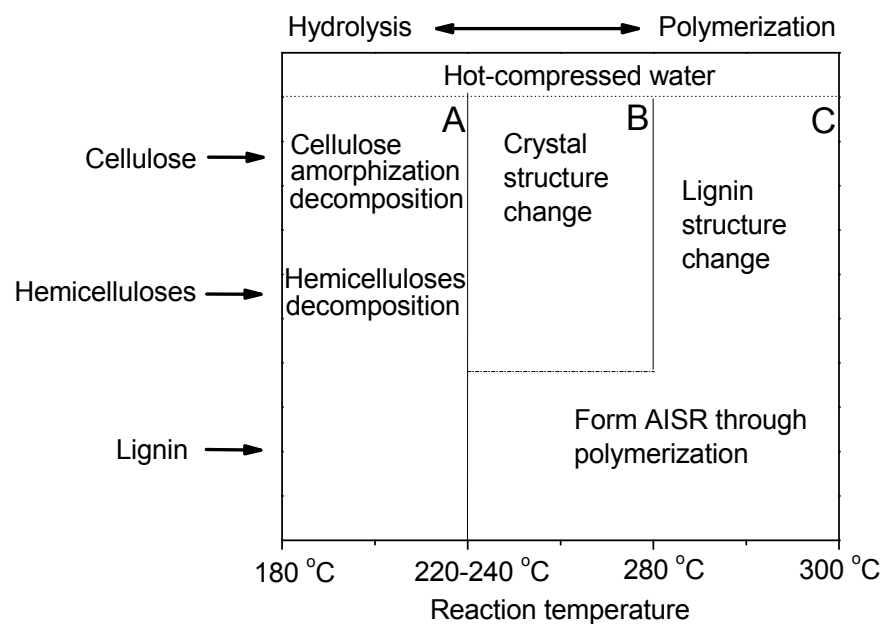

Scheme 1. Mechanisms for the formation of carbonyl groups in AISR.

1. $\mathrm{H}_{2} \mathrm{O} \stackrel{\text { High temperature }}{\longrightarrow} \mathrm{H}^{\oplus}+\mathrm{OH}^{\ominus}$

2.

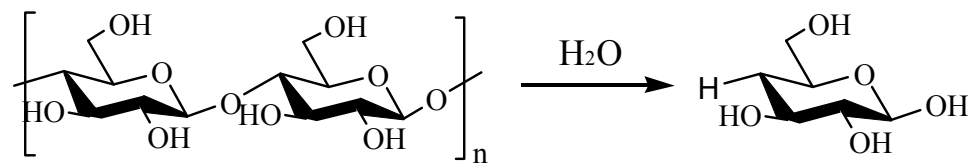

3.

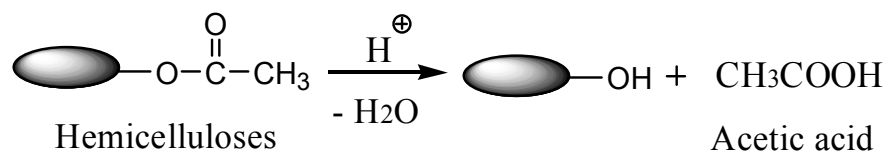

4.

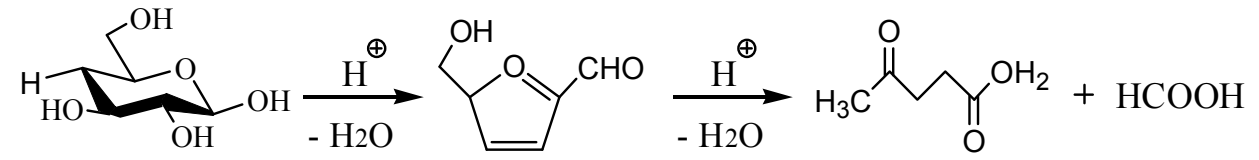

Glucose HMF higher severity levulinic acid formic acid

5.

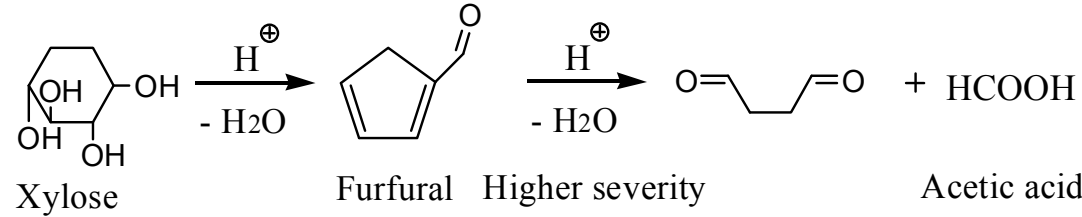

6

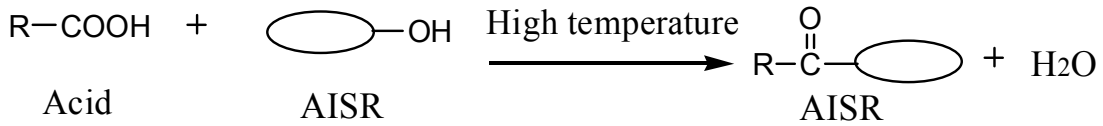


Scheme 1(1-5) shows the reaction pathways of the formation of weak acids. With an increase in temperature, the acids and AISR polymerized to form a carbonyl group structure, as shown in Figure $5 \mathrm{~b}$. The mechanism of the formation of carbonyl group is shown in Scheme 1. For the hydrothermal liquefaction of cypress at $280-300{ }^{\circ} \mathrm{C}$, the AISR yield result (Figure 2) indicated that the yield was higher than that of treatment at $180^{\circ} \mathrm{C}$. The assumed mechanism was that the re-polymerization of the polysaccharide degradation products such as furfural and HMF with each other and/or polymerization with AISR/lignin (Scheme 2) formed a lignin-like material termed pseudo-lignin [33,34].

Scheme 2. Formation of AISR through polymerization of HMF and furfural with lignin.
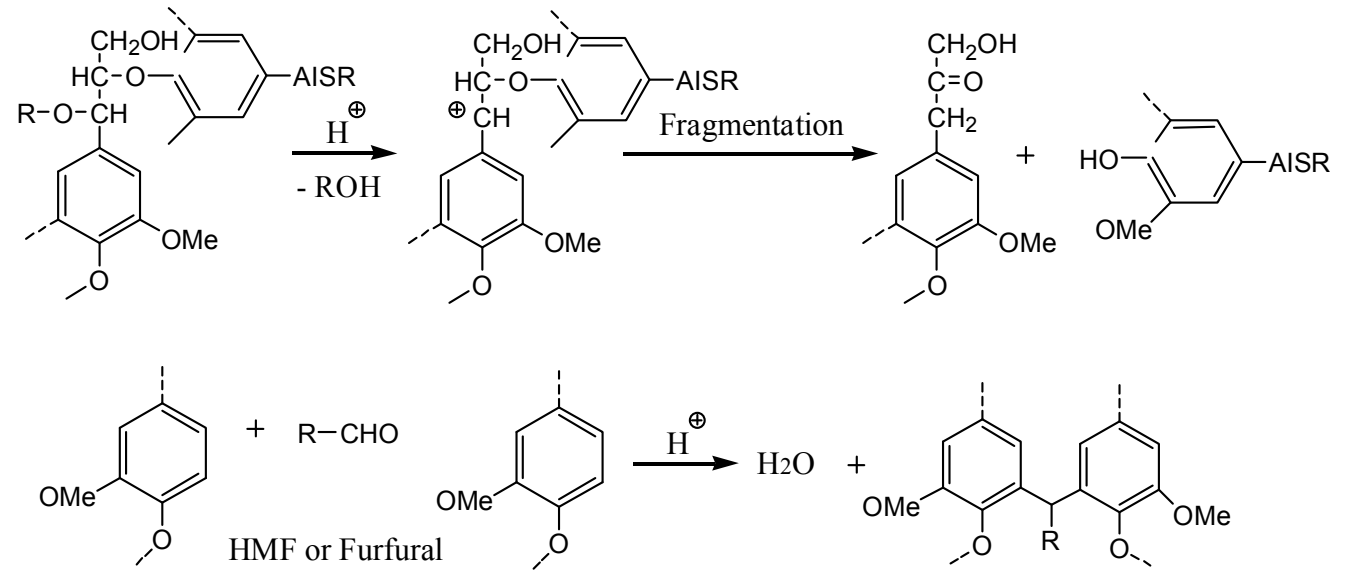

\section{Conclusions}

The yield of acid-insoluble solid residue initially decreased with the increase in temperature from 180 to $220^{\circ} \mathrm{C}$, and then increased after treatment at $220^{\circ} \mathrm{C}$. The reactive fragments produced from degradation of cypress transformed into acid-insoluble solid residue in the form of carbon and oxygen through polymerization reactions. The ASSR yield decreased over the whole temperature (180 to $300{ }^{\circ} \mathrm{C}$ ), while the increase of AISR yield started after $220{ }^{\circ} \mathrm{C}$. The polymerization reaction also mainly ocurred at lower temperatures. Compared with temperature, reaction time had a lesser influence on the SR yield. The yield of AISR increased as the ASSR yield decreased with reaction time. The majority of cellulose in cypress was decomposed at 280 and $300^{\circ} \mathrm{C}$. Hemicelluloses were decomposed to small compounds at the initial stage, and then these compounds likely rearranged through polymerization to form AISR after $240{ }^{\circ} \mathrm{C}$. The structure of $\mathrm{C}-\mathrm{H}$ in-plan bending in guaiacyl lignin disappeared after $280^{\circ} \mathrm{C}$ and the "core" of the lignin structure slightly changed at $300{ }^{\circ} \mathrm{C}$. The HHV of the SRs obtained at 260 to $300{ }^{\circ} \mathrm{C}$ were $23.4-26.3 \mathrm{MJ} / \mathrm{kg}$ and they were suited for combustion as a solid fuel.

\section{Acknowledgments}

This work was supported by the China Ministry of Education (111), the National Natural Science Foundation of China (31110103902), and the Major State Basic Research Projects of China (973-2010CB732204/1). 


\section{References}

1. Zhang, X. Study on biomass pyrolysis kinetics. J. Eng. Gas. Turbines Power 2006, 128, 493-496.

2. Zhang, B.; Keitz, M.; Valentas, K. Thermochemical liquefaction of high-diversity grassland perennials. J. Anal. Appl. Pyrol. 2009, 84, 18-24.

3. Fan, S.P.; Zakaria, S.; Chia, C.H.; Jamaluddin, F.; Nabihah, S.; Liew, T.K.; Pua, F.L. Comparative studies of products obtained from solvolysis liquefaction of oil palm empty fruit bunch fibres using different solvents. Bioresour. Technol. 2011, 102, 3521-3526.

4. Lin, L.Z.; Yao, Y.; Yoshioka, M.; Shiraishi, N. Liquefaction mechanism of cellulose in the presence of phenol under acid catalysis. Carbohydr. Polym. 2004, 57, 123-129.

5. Fang, Z.; Fang, C. Complete dissolution and hydrolysis of wood in hot water. AIChE J. 2008, 54, 2751-2758.

6. Fang, Z.; Minowa, T.; Smith, R.L.; Ogi, T.; Kozinski, J.A. Liquefaction and gasification of cellulose with $\mathrm{Na}_{2} \mathrm{CO}_{3}$ and $\mathrm{Ni}$ in subcritical water at $350{ }^{\circ} \mathrm{C}$. Ind. Eng. Chem. Res. 2004, 43, 2454-2463.

7. Fang, Z.; Sato, T.; Smith, R.L.; Inomata, H.; Arai, K.; Kozinski, J.A. Reaction chemistry and phase behavior of lignin in high-temperature and supercritical water. Bioresour. Technol. 2008, 99, 3424-3430.

8. Yuliansyah, A.T.; Hirajima, T.; Kumagai, S.; Sasaki, K. Production of solid biofuel from agricultural wastes of the palm oil industry by hydrothermal treatment. Waste Biomass Valor. 2010, 1, 395-405.

9. Liu, W.W.; Hu, C.; Yang, Y.; Zhu, L.; Tong, D. Effect of the interference instant of zeolite HY catalyst on the pyrolysis of pubescens. Chin. J. Chem. Eng. 2010, 18, 351-354.

10. Kruse, A.; Gawlik, A. Biomass conversion in water at 330-410 and 30-50 MPa. Identification of key compounds for indicating differenct chemical reaction pathways. Ind. Eng. Chem. Res. 2003, 42, 267-279.

11. Xiao, R.; Chen, X.; Wang, F.; Yu, G. Pyrolysis pretreatment of biomass for entrained-flow gasification. Appl. Energy 2010, 87, 149-155.

12. Munir, S.; Daood, S.S.; Nimmo, W.; Cunliffe, A.M.; Gibbs, B.M. Thermal analysis and devolatilization kinetics of cotton stalk, sugar cane bagasse and shea meal under nitrogen and air atnospheres. Bioresour. Technol. 2009, 100, 1413-1418.

13. Brown, T.M.; Duan, P.; Savage, P.E. Characterization of product fractions from hydrothermal liquefaction of nannochloropsis sp. Energy Fuels 2010, 24, 3639-3646.

14. Lu, W.; Wang, C.; Yang, Z. The preparation of high caloric fuel (HCF) from water hyacinth by deoxy-liquefaction. Bioresour. Technol. 2009, 100, 6451-6456.

15. Xiu, S.; Shahbazi, A.; Shirley, V.B.; Wang, L. Swine manure/crude glycerol co-liquefaction: Physical properties and chemical analysis of bio-oil product. Bioresour. Technol. 2010, 102, 1928-1932.

16. Liu, H.M.; Xie, X.A.; Li, M.F.; Sun, R.C. Hydrothermal liquefaction of cypress: Effects of reaction conditions on 5-lump distribution and composition. J. Anal. Appl. Pyrol. 2010, 94, 177-183.

17. Segal, L.; Creely, L.; Martin, A.E.; Conrad, C.M. An empirical method for estimating the degree of crystallinity of native cellulose using the X-ray diffractometer. Text. Res. J. 1959, 29, 786-794. 
18. Xiu, S.; Shahbazi, A.; Shirley, V.; Cheng, D. Hydrothermal pyrolysis of swine manure to bio-oil: Effects of operating parameters on products yield and characterization of bio-oil. J. Anal. Appl. Pyrol. 2010, 88, 73-79.

19. Sun, P.; Heng, M.; Sun, S.H.; Chen, J. Analysis of liquid and solid products from liquefaction of paulownia in hot-compressed water. Energy Convers. Manag. 2011, 52, 924-933.

20. Hui, L.; Yuang, X.; Zeng, G.; Huang, D.; Huang, H.; Tong, J.; You, Q.; Zhang, J.; Zhou, M. The formation of bio-oil from sludge by deoxy-liquefaction in supercritical ethanol. Bioresour. Technol. 2010, 101, 2860-2866.

21. Ando, H.; Sakaki, T.; Kokusho, T.; Shibata, M.; Uemura, Y.; Hatate, Y. Decomposition behavior of plant biomass in hot-compressed water. Ind. Eng. Chem. Res. 2000, 39, 3688-3693.

22. Akhtar, J.; Kuang, S.K.; Amin, N.S. Liquefaction of empty palmfruit bunch (EPFB) in alkaline hot compressed water. Renew. Energy 2010, 35, 1220-1227.

23. Demirbas, A. Competitive liquid biofuels from biomass. Appl. Energy 2011, 88, 17-28.

24. Xu, F.; Geng, Z.C.; Liu, C.F.; Ren, J.L.; Sun, J.X.; Sun, R.C. Structural characterization of residual lignins isolated with cyanamide-activated hydrogen peroxide from various organosolvs pretreated wheat straw. J. Appl. Polym. Sci. 2008, 109, 555-564.

25. Sun, J.X.; Xu, F.; Sun, X.F.; Sun, R.C.; Wu, S.B. Comparative study of lignins from ultrasonic irradiated sugar-cane bagasse. Polym. Int. 2004, 53, 1711-1721.

26. Sun, R.C.; Tomkinson, J.; Wang, S.Q.; Zhu, W. Characterization of lignins from wheat straw by alkaline peroxide treatment. Polym. Degrad. Stabil. 2000, 67, 101-109.

27. Wang, C.; Pan, J.; Li, J.; Yang, Z. Comparative studies of products produced from four different biomass samples via deoxy-liquefaction. Bioresour. Technol. 2008, 99, 2778-2786.

28. Xiao, R.; Zhang, M.; Jin, B.; Huang, Y. High-temperature air/steam-blown gasification of coal in a pressurized spout-fluid bed. Energy Fuels 2006, 20, 715-720.

29. Kuchonthara, P.; Bhattacharya, S.; Tsutsumi, A. Combination of thermochemical recuperative coal gasification cycle and fuel cell for power generation. Fuel 2005, 84, 1019-1021.

30. Foston, M.; Ragauskas, A.J. Changes in lignocellulosic supramolecular and ultrastructure during dilute acid pretreatment of populus and switchgrass. Biomass Bioenergy 2010, 34, 1885-1895.

31. Stephens, C.; Whitmore, P.; Morris, H.; Bier, M. Hydrolysis of the amorphous cellulose in cotton-based paper. Biomacromolecules 2008, 9, 1093-1099.

32. Emelsy, A.; Heywood, R. On the kinetics of degradation of cellulose. Cellulose 1997, 4, 1-5.

33. Li, J.B.; Henriksson, G.; Gellerstedt, G. Carbohyhydrate reactions during high-temperature steam treatment of aspen wood. Appl. Biochem. Biotechnol. 2005, 125, 175-188.

34. Li, J.B.; Henriksson, G.; Gellerstedt, G. Lignin depolymerization/repolymerization and its critical role for delignification of aspen wood by steam explosion. Bioresour. Technol. 2007, 98, 2329-2335.

(C) 2013 by the authors; licensee MDPI, Basel, Switzerland. This article is an open access article distributed under the terms and conditions of the Creative Commons Attribution license (http://creativecommons.org/licenses/by/3.0/). 